\title{
(t)
}

\section{ATUAÇÃO DO SERVIÇO SOCIAL COM POPULAÇÃO LGBT EM CONTEXTO ULTRACONSERVADOR E PANDÊMICO}

\author{
Social work performance with LGBT population in ultraconservative and pandemic \\ context
}

Michael Hudson Dantas*

https://orcid.org/0000-0001-8495-9945
Luana Vanessa Soares Pinto de Souza**
https://orcid.org/0000-0002-8301-3936

\author{
Samya Katiane Martins Pinheiro*** \\ https://orcid.org/0000-0002-7742-2119
}

\section{RESUMO}

O objeto de análise desse estudo são as implicações do contexto ultraconservador e pandêmico para a atuação profissional do (a) assistente social no processo de atendimento e intermediação do acesso aos direitos da população LGBT a partir da experiência de atuação no Centro Municipal de Cidadania LGBT de Natal (RN). A metodologia utilizada parte da reflexão ética, por meio de reuniões e estudos temáticos a partir das demandas do Centro LGBT de Natal (RN) e a análise bibliográfica, tendo em vista apreensão crítica da totalidade da vida social. Assim, temos o entendimento que o aprofundamento da desigualdade social, em tempos de pandemia sanitária é parte fundamental da sociabilidade do

\footnotetext{
* Assistente Social. Mestre em Serviço Social. Assistente Social do Centro Municipal de Cidadania LGBT de Natal (RN). (CEMCID, Natal, Brasil). Av. Nascimento de Castro, no. 2024, Lagoa Nova, Natal (RN), CEP.: 59054-180. E-mail: michaelhudsondantas@gmail.com.

** Assistente Social. Mestranda em Serviço Social pelo Programa de Pós-graduação em Serviço Social da Universidade Federal do Rio Grande do Norte (UFRN, Natal, Brasil). Av. Sen. Salgado Filho, no. 3000 - Lagoa Nova, Natal (RN), CEP.: 59064-720. Assistente Social do Centro Municipal de Cidadania LGBT de Natal (RN). (CEMCID, Natal, Brasil). Endereço: Av. Nascimento de Castro, no. 2024, Lagoa Nova, Natal (RN), CEP.: 59054-180. E-mail: lua.soares16@gmail.com.

${ }^{* * *}$ Assistente Social. Mestra em Serviço Social. Doutoranda do Programa de Pós-graduação em Serviço Social da Universidade Federal do Rio Grande do Norte (UFRN, Natal, Brasil). Endereço: Av. Sen. Salgado Filho, no. 3000, Lagoa Nova, Natal (RN), CEP.: 59064-720. Assistente Social do Centro Municipal de Cidadania LGBT de Natal (RN). (CEMCID, Natal, Brasil). Endereço: Av. Nascimento de Castro, no. 2024, Lagoa Nova, Natal (RN), CEP.: 59054-180. E-mail: samyakatiane@hotmail.com.
}

DOI 10.22422/temporalis.2021v21n41p155-172 Creative Commons Atribuição 4.0 Internacional (https://creativecommons.org/licenses/by/4.0/deed.pt BR), que permite copiar e redistribuir o material em qualquer suporte ou formato, bem como adaptar, transformar e criar a partir deste material para qualquer fim, mesmo que comercial. O licenciante não pode revogar estes direitos desde que você respeite os termos da licença. 


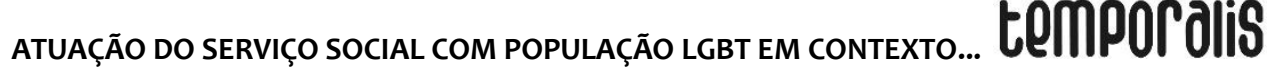

capital e o ataque orquestrado pela classe dominante heteropatriarcal e racista contra a vida de trabalhadores(as), em toda sua diversidade, é inerente ao projeto de hegemonia social do capital, o que impacta, indiscutivelmente, o exercício profissional de assistentes sociais, uma vez que essa atuação é direcionada ao enfrentamento das expressões da questão social e se pauta em projeto contra-hegemônico de sociedade.

\section{PALAVRAS-CHAVE}

Conjuntura brasileira. Ultraconservadorismo. Pandemia. LGBT. Serviço social.

\section{ABSTRACT}

The object of analysis of this study are the implications of the ultraconservative and pandemic context for the professional performance of the social worker in the process of assisting and intermediating access to the rights of the LGBT population from the experience of working at the Municipal Center for LGBT Citizenship in Natal (RN). The methodology used is based on ethical reflection, through meetings and thematic studies based on the demands of the LGBT Center in Natal (RN) and the bibliographic analysis, with a view to critical apprehension of the totality of social life. Thus, we understand that the deepening of social inequality, in times of health pandemic, is a fundamental part of the sociability of capital and the orchestrated attack by the heteropatriarchal and racist ruling class against the lives of workers, in all their diversity, is inherent. to the project of social hegemony of capital, which undoubtedly impacts the professional practice of social workers, since this action is directed at facing the expressions of the social issue and is guided by a project against the hegemonic of society.

\section{KEYWORDS}

Brazilian conjuncture. Ultraconservatism. Pandemic. LGBT. Social work.

Submetido em: 21/3/2021.

Aceito em: 10/6/2021.

\section{INTRODUÇÃO}

A conjuntura brasileira e mundial tem sido permeada pelo recrudescimento do ultraconservadorismo, regressão de direitos, contrarreformas do Estado, aumento da violência e intensificação da exploração/opressão a que está submetida a classe trabalhadora em toda a sua diversidade, especialmente em se tratando das mulheres, de negros(as) e da população de lésbicas, gays, bissexuais, travestis e transexuais (LGBT) $)^{1}$.

O feminicídio, a LGBTfobia e o extermínio da juventude negra crescem a cada dia, sob dados alarmantes que, na verdade, talvez nem retratem a real situação pela qual se insere essa parcela populacional, dada a subnotificação dos crimes e formas de violência. Além disso, vemos notícias diárias sobre cortes em políticas públicas, retrocessos em direitos trabalhistas, previdenciários, na política de educação, saúde etc. Tudo isso demonstra o quanto o capitalismo obteve sucesso em seu projeto de

\footnotetext{
${ }^{1}$ Nesse trabalho, optamos pelo uso da sigla LGBT em razão de alguns aspectos: 1 - o acúmulo do próprio movimento LGBT sistematizado nas Conferências Nacionais de Direitos em que essa nomenclatura foi a última aprovada; 2 - dada a diversidade de siglas existentes no âmbito desse movimento, das quais consideramos importantes sob o ponto de vista da visibilidade de identidades e expressões da orientação sexual, mas temos o entendimento de que uma sigla que nomeia uma população cuja complexidade é profunda, dificilmente contemplará todas, o que nos leva a utilizar a eleita nos espaços de debate coletivo, como é o caso das conferências, mesmo com todos seus limites ; 3 - e, por último, dada a difusão social da sigla tanto em termos de alcance popular quanto das próprias políticas públicas e sociais.
} 
sociedade: explorar, oprimir, coisificar seres humanos, torná-los descartáveis e utilizá-los a seu bel-prazer para obtenção de lucro.

A conjuntura perpassada por uma crise estrutural do capital já impõe, por si só, imensos desafios à vida de trabalhadores e trabalhadoras. No entanto, o momento é também de avanço de uma extrema-direita ultraconservadora sob o ponto de vista econômico e moral, com fortes traços fascistas e violentos. No Brasil, um dos marcos da ascensão ultraconservadora e ultraneoliberal para consolidação do projeto de direção da nação, em nossa análise, é o golpe sofrido pela então presidenta Dilma Roussef (PT), em 2016.

A ascensão bolsonarista é expressão de todos esses movimentos da conjuntura. Logo, não é aleatória. Bolsonaro (sem partido) conseguiu condensar os anseios de uma burguesia nacional e internacional, sob os aspectos da intensificação da política neoliberal de ajuste fiscal e das vertentes ultraconservadoras moralmente, com visível caçada contra mulheres, LGBT, negros(as) e indígenas.

Também não é à toa nem tampouco pode parecer surpresa que o Brasil seja, há alguns anos, o campeão mundial de mortes de LGBT no mundo - à frente, inclusive, de países em que a homossexualidade é oficialmente proibida e punida com pena de morte. Os dados produzidos pelo Grupo Gay da Bahia (GGB), sistematizados no Relatório Mortes Violentas de LGBT $+^{2}$ no Brasil, demonstram que em 2016, 2017, 2018 e 2019 foram mortos respectivamente 343, 445, 420, e 329 LGBT no país em decorrência da LGBTfobia, respectivamente. É reflexo de uma sociedade forjada no heteropatriarcalismo, que escolhe diariamente aniquilar a diversidade humana para garantir a hegemonia dos dominantes. Trata-se de uma expressão da necropolítica, ou política da morte, como afirma Mbembe (2018).

Diante de toda a complexidade da conjuntura, em 2020 o mundo ainda experimenta uma nova pandemia sanitária, gerada pelo novo coronavírus, causador da COVID-19. O Brasil é um dos campeões mundiais de mortes em decorrência do referido vírus. Até início de junho de 2021, temos a infeliz marca de mais 470 mil mortes em decorrência da pandemia (esse número cresce a cada dia e nunca, desde o início, esteve em média tão alta quantos nesses últimos meses).

Todas essas questões impõem ao serviço social, como uma das profissões da linha de frente no enfrentamento à pandemia - seja na saúde, assistência social ou demais espaços sócio-ocupacionais - imensos e complexos desafios para a atuação profissional. Ademais, o projeto ético-político da profissão vai de encontro ao projeto ultraconservador e ultraneoliberal em andamento no país.

A partir dessas reflexões, elege-se como objetivo geral desse artigo analisar os desafios da atuação profissional do serviço social na intermediação do acesso aos

${ }^{2}$ O Grupo utiliza a sigla LGBT acrescida do + em razão de também ocorrerem assassinatos de pessoas heterossexuais em decorrência da LGBTfobia, como em casos que a morte se dá pela tentativa de defesa de um LGBT, por ser confundido com LGBT, ou dos chamados T-lovers, heterossexuais (ou bi) que se relacionam com travestis ou transexuais. 


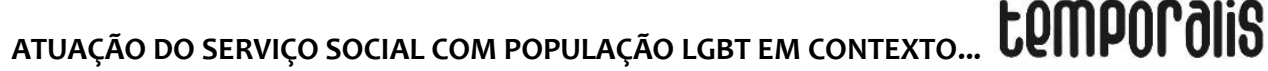

direitos da população LGBT em contexto ultraconservador e pandêmico, a partir da experiência no Centro Municipal de Cidadania LGBT do município de Natal (RN).

Com tal propósito, estruturamos este artigo em dois momentos: o primeiro, com uma análise sobre a conjuntura brasileira do pós-golpe contra o mandato da presidenta Dilma Roussef (PT), em 2016; o segundo, com as reflexões apreendidas no desenvolvimento dos trabalhos no Centro Municipal de Cidadania LGBT de Natal (RN) sobre os desafios para a atuação do serviço social na garantia de direitos desse segmento populacional.

\section{CONJUNTURA BRASILEIRA E O ATAQUE ORQUESTRADO CONTRA A DIVERSIDADE HUMANA}

No cenário político e econômico brasileiro, o fim dos governos Lula e início da gestão de Dilma Rousseff, ambos petistas, foram marcados por turbulências econômicas e políticas que impactaram frontalmente a conjuntura mais recente do país, principalmente o desenrolar do golpe sofrido pela então presidenta em 2016.

Durante seu governo e especialmente nas campanhas, Dilma sofreu diversos ataques machistas e LGBTfóbicos. Quando agia de maneira mais dura, rapidamente a acusavam de lésbica (ou sapatão, termo utilizado para depreciar) ou mesmo autoritária. Foram disseminados em massa e motivos de piadas em milhões de compartilhamentos nas redes sociais, por exemplo, adesivos em que Dilma aparecia de pernas abertas nas entradas de combustível dos automóveis, onde a bomba de abastecimento simulava uma penetração. Ataques, por sinal, que apenas uma mulher sofreria nessa intensidade (quando um homem os sofre, geralmente é taxando-o de homossexual em sentido pejorativo).

Boulos (2016) analisa que estamos passando por uma Onda Conservadora, observada desde 2013 no país. "Conservadora não no sentido de manter o que está aí, mas no pior viés do conservadorismo político, econômico e moral. Uma virada à direita" (BOULOS, 2016, p. 29). Diríamos que se trata de uma virada à extrema direita. A bancada legislativa eleita em 2014 fora, até aquele momento, a mais conservadora desde a ditadura. "O ano de 2015, portanto, já se iniciou sob o signo da reação e do conservadorismo" (DEMIER, 2016, p. 14).

Demier (2016) menciona que no contexto pré-golpe, em março de 2015, o Brasil experimentou o fenômeno de retorno das direitas às ruas. Essa direita com expressa demonstração de seu caráter conservador e retrógrado, constituído massivamente pela classe média insatisfeita com o governo federal, bradava a necessidade de rever as políticas de redistribuição de renda (como o Programa Bolsa Família, sob o argumento da meritocracia) e de reduzir a maioridade penal. Ademais, com o apoio irrestrito da bancada evangélica atacava políticas públicas em defesa dos direitos das mulheres, inclusive o direito assegurado ao aborto legal, em casos de estupro.

Vestidos com a camisa da seleção brasileira de futebol, os integrantes da extremadireita pregavam um nacionalismo pequeno-burguês violento, saudosista da ditadura 
militar e eram convocados pelos movimentos que emergiram naquele momento de maneira bastante oportunista, como o Movimento Brasil Livre (MBL) - em explícita referência ao Movimento Passe Livre, que convocara parte das manifestações de 2013, com direção social oposta - o Revoltados Online e o Vem Pra Rua. As redes sociais cumpriram e ainda cumprem papel fundamental nesse contexto, palco tanto das mobilizações para os atos de rua, quanto da disseminação das notícias falsas sobre a presidenta e demais políticos ligados à esquerda brasileira, as chamadas Fake News (DEMIER, 2016).

Esse movimento saudosista da ditadura cresce exponencialmente nos anos posteriores no país. A pauta da anticorrupção era sempre uma bandeira levantada sob o argumento para o retorno dos militares ao poder, pois se afirmava não ter havido corrupção na ditadura de 1964-1985 (uma formulação completamente falseadora da realidade). Nos anos do golpe ao governo Dilma esse era um dos elementos mais utilizados.

A votação do impeachment de Dilma, na Câmara dos Deputados foi uma verdadeira cena de horrores, expressão da barbárie, ultraconservadora e com traços fascistas. As inúmeras invocações e homenagens, no momento da deflagração dos votos (em nome de Deus e da família, em nome dos militares de 1964, etc.), representa bem o cenário macabro daquele período (que se estende aos dias atuais). Em suas casas, milhões de brasileiros(as) assistiam à votação, alguns perplexos e sem acreditar no que se passava, outros vestidos como que para um jogo de final da copa do mundo em que o time brasileiro seria favorito, com suas camisas da seleção brasileira de futebol, comemorando um momento que mal sabiam das repercussões desastrosas em suas vidas (até hoje, muitos/as não sabem ou preferem não saber). Tratava-se de um contexto de avanço ultraconservador e de uma verdadeira caçada contra as mulheres, LGBT e negros(as), bem como a todas as pautas que se relacionem a estes segmentos. Dito de outro modo, engendrou-se um golpe heteropatriarcal, LGBTfóbico e racista, além de burguês.

Quinalha (2016) ressalta que esse golpe tem três facetas: corrupção, neoliberalismo e conservadorismo ${ }^{3}$, que se apresentam enquanto um conjunto articulado para garantir a hegemonia do Estado nacional. Salienta-se que essas três dimensões são essenciais para o golpe, pois, se livrariam dos processos de corrupção, intensificariam a política de austeridade a um nível que os governos petistas não conseguiriam, ou teriam mais dificuldades, muito em razão da sua base social. Atacariam, ademais, quem eles mais odeiam em termos de humanidade: as mulheres, negros(as) e LGBT. É um golpe “[...] tramado e executado por homens brancos, heterossexuais e

\footnotetext{
${ }^{3}$ Sobre essas facetas, sinaliza: "[...] a primeira e mais visível delas é o impulso de autopreservação do establishment político que busca, a qualquer custo, escapar das investigações criminais. A segunda, por sua vez, é o desmonte da precária proteção social que esse governo interino pretende. Por fim, a terceira dimensão desse golpe é a restrição de direitos civis e políticos dos setores mais vulneráveis da sociedade, minando os poucos mecanismos de proteção dos direitos humanos e aumentando o poder de agenda e de veto dos setores religiosos fundamentalistas no novo governo. 'Em nome de Deus e da família' é o lema que indica o tamanho do buraco em que estamos entrando, sobretudo mulheres, negros e LGBTs" (QUINALHA, 2016, p. 133).
} 
cisgêneros [...]" (QUINALHA, 2016, p. 134), não apenas em termos de identidades pessoais, mas ideológicas. Repudiam a existência de LGBT e comemoram, quando não são responsáveis diretos, agora sem qualquer constrangimento, as violências pelos quais esses sofrem. É uma expressão da barbárie aprofundada pelo golpe.

É imperioso afirmar que se trata de um golpe contrário aos princípios democráticos e aos direitos humanos. E sobre o atual Chefe de Estado do país, “[...] pode-se dizer que chega à presidência, por um atalho, uma moral sexual retrógrada, centrada em um modelo único de família como célula elementar da sociedade" (QUINALHA, 2016, p. 137).

Para Anderson (2020), outro dos elementos importantes da conjuntura é o assenso de uma nova religião tomando conta das massas populares, da qual, segundo menciona, por volta de 2015, já fazia parte de mais 20\% da população nacional: 0 protestantismo evangélico. Parcela importante das igrejas neopentecostais evangélicas funciona como verdadeiras empresas, gerando superlucros para seus donos. $O$ autor analisa que as igrejas brasileiras não possuem um perfil ideológico bem definido, exceto quando se trata dos temas como aborto e direitos LGBT. Flutuam com muita facilidade de governo em governo, apoiando e recebendo apoio. $\mathrm{O}$ ataque orquestrado é direcionado às mulheres e à população LGBT, do qual não abrem mão e intervém diretamente quando da possibilidade de formulação de qualquer projeto de lei ou proposta de política pública, voltado a esses segmentos.

A bancada evangélica - da qual as igrejas como a Universal e Assembleia de Deus têm diversos representantes em todos os poderes (legislativo, executivo e judiciário em âmbito federal, estaduais e municipais) - conforma um bloco de poder junto às bancadas da Bala e do Boi que objetiva dirigir a nação, sob dogmas religiosos e moralistas. Por conseguinte, é um projeto de direção social, de dominação, de hegemonia.

O cenário esteve armado, portanto, para o assenso de Bolsonaro à presidência do país. Ele tinha disposição e interesse em seguir à risca a agenda ultraneoliberal (tanto que tomou como uma das grandes figuras de sua campanha o economista Paulo Guedes $^{4}$ ), representava os anseios conservadores de ataque aos direitos humanos, sem constrangimentos quanto ao fato de reivindicar a pauta da bancada evangélica agora no poder executivo federal, assim como representava a ideia de um sujeito fora da ordem da corrupção, pretensamente honesto, com coragem para combater a corrupção - seria, como faziam/fazem questão de afirmar, o fim da mamata.

"O reacionarismo com flertes e fantasias fascistas não é o oposto nem o avesso do golpe; é uma de suas balizas e uma de suas variáveis de sustentação" (MASCARO, 2019, p. 26). Ao assumir a presidência, Bolsonaro nomeia o juiz Sérgio Moro como Ministro da Justiça de seu governo, pagando a conta pela sua enorme contribuiçã̃o

\footnotetext{
${ }^{4}$ Guedes é um economista brasileiro, mestre e doutor pela Universidade de Chicago, foi uma das principais figuras da campanha de Bolsonaro, como o responsável por sua política econômica. Declaradamente neoliberal, não disfarçou suas intenções: intensificar o ajuste fiscal e a política de austeridade.
} 
ao golpe, por meio, por exemplo, da prisão do principal oponente eleitoral de Bolsonaro em 2018 e o favorito na corrida presidencial: Lula (PT). Essa nomeação escancara a atuação direcionada ideologicamente da Operação Lava Jato - "[...] perde o pudor do consórcio ao bolsonarismo" (MASCARO, 2019, p. 30).

Para Mascaro (2019), Temer e Bolsonaro se assemelham sob o ponto de vista da atuação econômica neoliberal, seguindo a mesma linha, ambos desenvolvem uma política submissa aos Estados Unidos. Além disso, o autor chama a atenção para a relação da política Bolsonarista com o militarismo, os quais ocuparam muitos dos cargos de seu governo, além de seu vice-presidente ser um general da reserva do Exército brasileiro, Hamilton Mourão (PRTB). Uma das bandeiras mais levantadas em campanha reside na liberalização das armas, por exemplo.

Não bastassem todos os ataques, em 2020 o mundo ainda experimenta uma nova pandemia sanitária, gerada pelo vírus da COVID-19. Antunes (2020) em texto bastante elucidativo sobre as consequências da pandemia para a classe trabalhadora, lança algumas análises chave para entendermos quais são estas implicações. De início, já afirma que faz parte da lógica do capital a destrutividade. Não é novidade. Essa é a sua normalidade. O autor nomeia essa "[...] imbricação trágica entre sistema de metabolismo antissocial do capital, crise estrutural e explosão do coronavírus [...]" de "[...] capital pandêmico" (ANTUNES, 2020, não paginado).

O Brasil também é um dos campeões mundiais de mortes em decorrência do novo coronavírus. Até início de junho de 2021, foram mais de 17 (dezessete) milhões de casos e mais de 470 (quatrocentas e setenta) mil mortes em decorrência desse vírus no país. Mas, há uma questão que deve ser lembrada: a desigualdade, o desemprego estrutural, a superexploração e precarização do trabalho não são elementos trazidos pelo coronavírus e fazem parte da realidade capitalista há bastante tempo. Contudo, nesse cenário, "[...] além dos altíssimos índices globais de mortalidade, ampliam-se enormemente $\mathrm{o}$ empobrecimento e a miserabilidade na totalidade da classe trabalhadora" (ANTUNES, 2020, não paginado).

A conjuntura do capital pandêmico coloca desafios ainda mais intensos para a sobrevivência concreta da classe que precisa trabalhar para viver. A escolha, durante esse processo, foi e continua sendo difícil: sair para trabalhar e arriscar a se contaminar e, possivelmente, morrer; ou ficar dentro de casa em isolamento social e morrer de fome por falta de dinheiro para pôr comida na mesa. Não é difícil de imaginar o que acontece.

Diante de um Brasil bolsonarista - e suas diversas interdições à possibilidade de garantia de uma renda extra emergencial para assegurar o isolamento social de trabalhadores(as) informais, desempregados(as) e microempreendedores(as) -, muitas vidas foram tiradas. Para Antunes (2020), a classe trabalhadora encontra-se sob fogo cruzado, uma vez que é necessário o isolamento social para evitar o contágio pelo coronavírus, "Mas como ficarão em isolamento social os/as desempregados/as, os/as informais, os trabalhadores/as intermitentes, os/as 
AtuaÇÃo do SERViço social com População lgbt em contexto...

uberizados/as, os/subutilizados/as, os/as terceirizados/as [...]"? (ANTUNES, 2020, não paginado).

No Brasil, Bolsonaro deu um ótimo exemplo de como não agir: desresponsabilizouse pelo tratamento da questão, desacreditou a dimensão que o vírus tomaria (chamou publicamente de gripezinha, por exemplo), desqualificou as análises sérias sobre o tema, negando constantemente a ciência, tendo como um dos exemplos sua compra em massa de um medicamento sem comprovada eficácia (Hidroxicloroquina5), apenas como uma tentativa populista e desonesta de falsear a realidade; além de dificultar a garantia de vacinas ${ }^{6}$ para toda a população. 0 negacionismo da ciência é outro elemento importante dessa conjuntura, a qual tem o presidente como um dos principais entusiastas. Chega a ser criminosa a ação de Bolsonaro e sua equipe ante o enfrentamento da COVID-19 em nosso país.

Mas, a pandemia, o isolamento social e a necessidade de parar parte da produção evidenciaram uma dimensão básica dessa sociedade, a que Marx e os marxistas sempre afirmaram: a única mercadoria que gera valor é o trabalho. Sem trabalhadores(as) não há produção e, portanto, não há geração de riqueza e maisvalia. A pandemia joga luz sobre algumas desigualdades latentes, mas invisibilizadas.

Antunes (2020) assinala que algumas das principais tendências do trabalho para os próximos anos são o incremento e acentuação do trabalho em home office, teletrabalho e Ensino à Distância (EAD), no caso da educação. Além disso, ainda argumenta que será uma realidade de mais desemprego e mais desigualdade social, "[...] e quem 'tiver a sorte' de permanecer trabalhando, vivenciará um nefasto binômio: maior exploração e mais espoliação" (ANTUNES, 2020, não paginado).

Nessa esteira, trabalhadores(as) negros(as), mulheres e LGBT, em razão da sua inserção já desigual nessa seara capitalista são os(as) mais afetados(as). O isolamento social elevou os números de violência contra as mulheres, haja vista o convívio mais intenso com seus algozes nos lares, sem mencionar o aumento da exploração dos seus corpos e do seu trabalho, por estarem todos, por mais tempo, em casa; o aprofundamento do racismo estrutural7 ${ }^{7}$ se expressa nas batidas policiais

\footnotetext{
${ }^{5}$ Esse é um medicamento fármaco já existente, usado para tratamento de algumas doenças (como artrite reumatoide e lúpus eritematoso) e foi indicado, em grande parte, pelo então presidente dos EUA, Trump, em meios às tentativas de encontrar tratamento para esse novo vírus. No entanto, diversas pesquisas demonstraram que não tinham qualquer comprovação de eficácia no tratamento da COVID-19. Bolsonaro, mesmo ciente da possível ineficácia, realizou compra em massa do referido medicamento para o país, obviamente com os recursos do SUS.

${ }^{6} \mathrm{O}$ ritmo de vacinação de brasileiros(as) é considerado extremamente lento e com muitas falhas: até início de junho de 2021, temos pouco mais de $10 \%$ da população brasileira totalmente imunizada (com as duas doses necessárias). Na intenção de apurar possíveis irregularidades na condução da pandemia, assim como identificar os motivos que causaram tantas mortes no país, instaurou-se, em finais de abril de 2021, a Comissão Parlamentar de Inquérito (CPI), também conhecida como CPI da COVID-19. Identificou-se, por exemplo, que o governo federal teria ignorado ou negado a compra de vacinas ainda em 2020 para dar início no mesmo ano.

7 "[...] o racismo é uma decorrência da própria estrutura social, ou seja, o modo 'normal' com que se constituem as relações políticas, econômicas, jurídicas e até familiares, não sendo um a patologia social e nem um desarranjo institucional. O racismo é estrutural” (ALMEIDA, 2019, p.50).
} 
nas favelas não deixaram de acontecer, mesmo nesse período, ou seja, o povo negro, majoritário nesses territórios, foi duplamente morto: pelo Estado e pela COVID-19; assim como para as mulheres, o maior tempo dentro dos lares representa maiores violências para LGBT também, em função de a família ser um dos seus maiores violentadores.

Portanto, não se pode afirmar que estamos todos(as) no mesmo barco. Nunca estivemos; logo, não seria diferente em um período de crise sanitária mundial. Se considerarmos a experiência das travestis e transexuais que, como demonstra dados da Associação Nacional de Travestis e Transexuais (ANTRA), estão 90\% em uma condição de prostituição, como elas puderam se isolar do risco do contágio pelo coronavírus se, em todos os momentos, tiveram de sair para trabalhar nas ruas? Ademais, como se deu o atendimento dessas pessoas nos serviços de saúde, ao se contaminarem e necessitarem do tratamento? Não é recente que a área de saúde não tem sido espaço de acolhimento para travestis e transexuais.

Para Antunes (2020, não paginado) “[...] a pandemia é o enfeixamento de um sistema que é letal em relação ao trabalho, à natureza, à 'liberdade substantiva' de todos os gêneros, raças, etnias, à plena liberdade sexual, dentre tantas outras dimensões do ser em busca de sua autoemancipação humana e social”. De acordo com o autor, o momento exige a formulação de táticas de enfrentamento dessa realidade. Não há como ficar apenas assistindo os "de cima" fazerem o que bem querem com nossas vidas.

\section{ATUAÇÃO DO SERVIÇO SOCIAL NO CENTRO MUNICIPAL DE CIDADANIA LGBT DE NATAL (RN) E OS DASAFIOS DO CONTEXTO DE REGRESSÃO DE DIREITOS E PANDEMIA DA COVID-19}

A violação de direitos humanos é uma das expressões da violência contra LGBT. Os seres sociais, especialmente aqueles que fazem parte dos segmentos que combinam opressão e exploração na vida cotidiana (como LGBT, mulheres e negros/as trabalhadores/as), são violentados nas mais diferentes formas nesta sociabilidade. A violência é perpassada por múltiplas determinações e pressupõe a existência de duas figuras (não necessariamente individualizadas, pois podem representar sujeitos coletivos): violentador e violentado. Quando se trata de LGBT, esses primeiros podem ser membros da família, pessoas desconhecidas, profissionais pelos quais convivem no cotidiano, companheiros(as) (ou ex) de relacionamento afetivo-sexual, mas, também, e em grande medida, esse papel fica a cargo do Estado.

Assim, intermediar o acesso aos direitos humanos para a população LGBT em meio a uma realidade de intensificação das contradições sociais, de avanço ultraconservador e ultraneoliberal e de pandemia sanitária é um desafio de tamanho incalculável e pressupõe o entendimento de que vivemos sob um Estado a serviço do capital. 
Sair de casa para alguns sujeitos representa medo, não apenas porque a cidade está violenta de uma forma geral, mas em razão da sua condição de opressões particularizadas que acentua e aumenta o leque de possibilidades de violências. $A$ população LGBT, negros(as) e mulheres, sabem bem o que é sentir medo cotidiano simplesmente por existir.

Em termos de políticas voltadas para o enfrentamento da violência LGBTfóbica e garantia de direitos humanos de LGBT, Feitosa (2019) analisa que um das importantes reivindicações do movimento $L G B T$, e uma das principais frentes de ação do Programa Brasil Sem Homofobia, que vem sendo atendida em alguns estados no país, é a instituição dos Centros de Referência para atendimento a essa população, semelhantes aos Centros de Referência Especializado de Assistência Social (CREAS) ${ }^{8}$.

No Nordeste brasileiro, constata-se a existência de 10 (dez) Centros de Referência 5 (cinco) estaduais e 5 (cinco) municipais (se consideradas as capitais nordestinas) -; apenas Alagoas e Maranhão não dispõem do equipamento, em nenhum âmbito. Trata-se de um equipamento fundamental no enfrentamento das situações de violência vivenciadas por LGBTs no cotidiano, em razão do trabalho interdisciplinar realizado e das possibilidades de intervenção profissional para potencializar o desenvolvimento e emancipação dos indivíduos e famílias atendidas, assim como a superação da situação de violência e violação de direitos.

O Programa Nacional de Direitos Humanos (PNDH3) (2009) prevê o fomento da criação de redes de proteção dos direitos humanos do segmento LGBT, especialmente a partir do apoio à implementação de Centros de Referência em Direitos Humanos e Combate à homofobia.

O Centro Municipal de Cidadania LGBT é fruto de uma reivindicação histórica dos movimentos LGBT em Natal (RN), atendida por meio do Decreto Municipal $n^{\circ} 11.909$, publicado em 5 de março de 2020. Está vinculado à Secretaria Municipal de Segurança Pública e Defesa Social (SEMDES), no âmbito do Departamento de direitos humanos 9 e tem a administração compartilhada com a Secretaria Municipal de Assistência Social (SEMTAS) e com a Secretaria Municipal de Saúde (SMS). Junto ao Centro LGBT (como vem sendo chamado popularmente), foi inaugurado no dia 30 de setembro de 2020, o Ambulatório Municipal para pessoas Transexuais e Travestis (Ambulatório TT) de Natal (RN). Os dois serviços são contrapontos a uma conjuntura de recrudescimento do ultraconservadorismo, autoritarismo e perda de direitos que vivenciamos no Brasil.

\footnotetext{
${ }^{8}$ Os CREAS são serviços do Sistema Único de Assistência Social (SUAS) e se destinam a atender e acompanhar pessoas e/ou famílias em situação de violência e violação de direitos. Neles, presta-se serviço de acompanhamento psicossocial e jurídico para impulsionar a superação das violências/violações.

9 Esse é um cenário em mudança, em razão da recém-criada Secretaria Municipal de Igualdade Racial, Direitos Humanos, Diversidade, Pessoas Idosas e Pessoas com Deficiência. O Centro de Cidadania LGBT deve ser vinculado a essa secretaria no período próximo.
} 
Alinhada ao governo federal, a gestão municipal do prefeito Álvaro Dias (PSDB) tem raízes no coronelismo, e a sua trajetória política em Natal (RN) é marcada pelo autoritarismo e negacionismo. Apesar das 6.295 mortes no estado, o prefeito da capital contribuiu para a desinformação da população propagando o tratamento precoce e distribuiu gratuitamente a ivermectina ${ }^{10}$, como a grande aposta para a prevenção e recuperação da COVID-19. Contraditoriamente, e numa evidente estratégia eleitoral, o então candidato atendeu a importantes reivindicações dos movimentos sociais. Destacamos aqui, além do Centro LGBT e Ambulatório TT, o Albergue Municipal $24 \mathrm{~h}^{11}$ para população em situação de rua, ambos criados no contexto da pandemia e pré-eleições municipais.

Outrossim, o modus operandi dessa gestão com os servidores municipais é de descaso e desrespeito. Além dos dezesseis anos sem reajuste salarial, foram obrigados a trabalhar desde o início da pandemia, completamente desprotegidos, sem acesso à testagem em massa, a equipamentos de proteção individual adequados e condições dignas de trabalho.

Os novos serviços não ficaram isentos da crise econômica, sanitária e política que atravessa o país. Especificamente, o Centro LGBT, que funciona com inúmeros limites, como a ausência de orçamento específico para o serviço, limitando a sua manutenção e a garantia de condições de trabalho para os profissionais. Carece de transporte adequado para realização das visitas domiciliares e institucionais, motorista, equipamentos de proteção individual necessários, e climatização compatível com a necessidade do serviço. Ademais, a falta de condições estruturais e de equipamentos adequados repercutiu na dificuldade para realização de atividades online e atendimentos remotos, que viessem a contribuir com o trabalho. Além da insuficiente oferta de benefícios eventuais como o de segurança alimentar (cesta básica), fundamentais em razão da realidade de desemprego e insegurança alimentar de parte significativa do público usuário.

O aprofundamento das múltiplas expressões da questão social, o pânico causado pelas notícias em torno dos números pungentes da pandemia, a necessidade do distanciamento e isolamento social, além das mortes de pessoas próximas, familiares e dos(as) próprios(as) trabalhadores(as), a ausência de um plano nacional de imunização e a não inclusão da classe trabalhadora do Sistema Único de Assistência Social (SUAS), que também se encontra na linha de frente ${ }^{12}$ do combate ao coronavírus, fazem com que a relação entre precarização do trabalho e saúde mental fique ainda mais estrita.

Segundo Souza (2021), deve-se reconhecer que a pandemia tem gerado graves problemas psicoemocionais, desde o medo do(a) trabalhador(a) em se infectar até o

\footnotetext{
${ }_{10}$ Um dos medicamentos apontados para o tratamento precoce da COVID-19, mesmo sem qualquer comprovação científica.

${ }^{11}$ Antes, o equipamento era voltado para o atendimento apenas no horário noturno.

${ }^{12}$ De acordo com o Decreto $n^{\circ} 10.282$, de 20 de março de 2020, que regulamenta a Lei $n^{\circ} 13.979$, de 06 de fevereiro de 2020, para definir os serviços públicos e as atividades essenciais.
} 
fato de ser um agente transmissor em potencial, levando o vírus para os seus familiares.

Entretanto, o serviço possibilitou que a população LGBT encontrasse um lugar de apoio e acolhimento diante do cenário pandêmico que tem uma repercussão mais aguda e destrutiva para esse segmento da sociedade. A necessidade do isolamento como estratégia de prevenção à disseminação do coronavírus potencializa um cenário de violações no âmbito familiar.

A não aceitação das diversas formas de expressão da sexualidade e identidade de gênero e a impossibilidade do contato com seus(as) parceiros(as) e amigos(as), os quais formam a principal rede de apoio para aqueles(as) que não conseguem este apoio junto a suas famílias, despertaram o agravamento do sofrimento psíquico. Segundo a pesquisa publicada pelo Coletivo Vote LGBT (2020), Diagnóstico LGBT+ na pandemia, em julho de 2020, a questão da saúde mental foi apontada por $42.72 \%$ dos participantes como a maior dificuldade enfrentada durante o isolamento social. Incluindo a ansiedade, depressão e crise de pânico. As outras questões apontadas referem-se às regras de convívio (16.58\%), solidão (11.72\%), e a falta de renda (10.62\%).

Não por acaso, a busca por psicoterapia está entre as principais demandas trazidas pelo público usuário do Centro LGBT, hoje. A necessidade de tratamentos psicoterapêuticos, identificada pelos(as) profissionais na assistência social, tem sido encaminhada para a rede local ou regional, vinculados à política pública de saúde, de acordo com a recomendação do Conselho Federal de Psicologia (2007). Contudo, em decorrência da defasagem do Sistema Único de Saúde (SUS) e da alta demanda de saúde mental na rede, nos impôs a necessidade de articulação com clínicas escolas de psicologia em instituições de ensino superior da rede pública e privada de Natal (RN), bem como, com uma escola de psicanálise da cidade ${ }^{13}$, estabelecendo fluxos de encaminhamentos para viabilizar o atendimento.

Cumpre mencionar que o Centro LGBT de Natal (RN) é formado por uma equipe técnica (composta por assistentes sociais, psicólogas, estatista, e uma coordenação técnica), e uma equipe administrativa (com recepção, coordenação administrativa e auxiliar de serviços gerais). A equipe técnica atua de forma interdisciplinar oferecendo dois serviços ao público usuário: o atendimento psicossocial e o Observatório LGBT de Natal (RN). O primeiro consubstancia-se por meio da realização de acolhimento e escuta qualificada, individual ou coletiva, à população LGBT e seus familiares, conforme suas necessidades específicas, e encaminhamentos à rede de atendimento, proteção social e garantia de direitos como forma de acesso aos serviços e benefícios socioassistenciais, qualificação profissional e acesso ao mercado de trabalho.

\footnotetext{
${ }^{13}$ No caso das Instituições de Ensino Superior (IES), os atendimentos são realizados por alunos no estágio final do processo de formação, já a escola de psicanálise dispõe dos alunos que já estão aptos para o atendimento profissional. Cabe a ressalva que para as pessoas transexuais ou travestis, a psicoterapia pode acontecer por meio do ambulatório municipal, que dispõe de uma psicóloga na sua equipe.
} 
Enquanto o Observatório LGBT objetiva sistematizar as informações sobre a população LGBT do município, na intenção de conhecer seu perfil socioeconômico, diversidade sexual e de gênero, relações familiares, dentre outras questões, além da importante coleta de dados nos diversos órgãos do Sistema de Garantia de Direitos e rede de atendimento, sobre casos de violência que tenha por fundamento a orientação sexual ou identidade de gênero, servindo de referência e base de dados. Estes também são produzidos no processo de atendimento e acompanhamento de usuários(as) desenvolvidos pelas equipes psicossociais, através de instrumentais específicos.

Compreendemos a interdisciplinaridade como uma prática que potencializa o serviço de atendimento à população LGBT e o exercício profissional de assistentes sociais, ainda que também represente um desafio. Para Carvalho (2012), o trabalho interdisciplinar está para além da presença de profissionais de diferentes áreas na mesma equipe, mas demanda, sobretudo, o abandono de posturas profissionais sectárias e centralizadoras.

Na verdade, uma profissão de maneira isolada não é suficiente para compreender o sujeito em sua totalidade e intervir na realidade social, contribuindo para o enfrentamento das diferentes expressões da questão social, abrangendo os direitos humanos em sua integralidade - não só a partir da ótica meramente orgânica, mas a partir de todas as necessidades relacionadas à sua qualidade de vida. Portanto, o trabalho interdisciplinar ao passo que é desafiador, é potencializador de ações e intervenções na realidade.

Além disso, temos a possibilidade de estabelecermos um acompanhamento conjunto com os profissionais de saúde que atuam no Ambulatório TT, possibilitando o atendimento à complexidade das demandas trazidas pelos(as) usuários(as) transexuais e travestis e contribuindo com a qualidade dos serviços prestados à comunidade. Esta relação interfere também no público do Centro, que embora não seja restrito à população transexual e travesti, tem nela sua principal demanda, representando $78 \%$ das pessoas em acompanhamento no serviço. Se por um lado, isso é expressão de esse ser o segmento que mais sofre com a invisibilidade, marginalização e abando das políticas públicas, por outro, impõe o desafio de ampliar o alcance do serviço aos demais segmentos LGBT.

Outra demanda expressiva no serviço é a orientação para retificação de nome e gênero no Registro de Nascimento e demais documentos. Um direito fundamental conquistado em 2018, por intermédio do Provimento $n^{\circ} 73 / 2018$ do Conselho Nacional de Justiça que extingue a necessidade de judicialização e comprovação da transexualidade, por meio da apresentação de laudos médicos e psicossociais. Contudo, para a efetivação desse direito são cobradas taxas cartoriais na emissão de algumas certidões dispostas na lista determinada no provimento, e da própria averbação, que seria a emissão de nova via do Registro com alteração do prenome e gênero. 
A negação também expõe a imbricação fundamental entre raça, classe e gênero, considerando o alto custo para realização desse processo. Embora o provimento nacional facilite o acesso a esse direito, não foi suficiente para garantir que todos(as) tenham acesso, considerando o custo alto $^{14}$ e a realidade socioeconômica desse segmento.

As articulações entre as instituições são essenciais na qualificação e desenvolvimento da nossa intervenção profissional, além da Política de assistência social e Defensoria Pública, destacamos a Universidade Federal do Rio Grande do Norte (UFRN) a partir do Observatório de Violência do Rio Grande do Norte e dos grupos de pesquisa ligados ao curso de serviço social ${ }^{15}$ que vêm atuando no sentido de estabelecer parcerias e desenvolver projetos de pesquisa.

A supervisão de estágio curricular, importante para a qualificação do atendimento aos usuários(as), a partir da troca de conhecimentos e experiência entre campo de atuação e o espaço de formação profissional, também é parte do nosso cotidiano. Segundo a Política Nacional de Estágio da Associação Brasileira de Ensino e Pesquisa do Serviço Social (2010), o estágio é caracterizado por sua dimensão teórico-prática, tendo como uma de suas premissas oportunizar à/ao discente o estabelecimento entre os conhecimentos teórico-metodológicos e o trabalho profissional, a capacitação técnico-operativa e o desenvolvimento de competências necessárias ao exercício da profissão.

No entanto, a crise sanitária impôs mudanças importantes no calendário acadêmico e suspensão das atividades presenciais. Apesar de inicialmente suspender os estágios, quando permite seu retorno, não assegura as condições adequadas para resguardar a saúde dos(as) estudantes, como a disponibilização de equipamentos de proteção adequados, além do corte de diversas bolsas, que dificultam o acesso aos campos de estágio. Reconhecemos a importância da atividade de estágio para 0 processo formativo, porém, o contexto pandêmico combinado com a falta de condições de trabalho adequadas implica na precarização da formação profissional e nos riscos de saúde coletiva.

É diante desse cenário avassalador que as assistentes sociais são convocadas a atuar profissionalmente. Um exercício profissional, crítico e consoante com o projeto profissional, vai de encontro a esse cenário ultraconservador e de profunda crise, com contornos ainda mais dramáticos com a pandemia. A ausência de políticas públicas específicas para garantia de direitos ao segmento LGBT no Brasil ainda é uma realidade latente.

Atuar consoante com o projeto profissional requer uma constante reflexão ética, para não cairmos na mecanicidade e reprodução dos valores hegemônicos racistas, cisgêneros e heteropatriarcais. A articulação com os movimentos sociais e o conselho

\footnotetext{
${ }^{14}$ No Estado do Rio Grande do Norte, tem custado em média R\$ 350,00.

${ }^{15}$ Especialmente: Grupo de Estudo e Pesquisa em Trabalho, Ética e Direitos (GEPTED); e Grupo de Estudo e Pesquisa em Questão Urbano-rural-ambiental, Movimentos Sociais e Serviço Social (QTEMOSS).
} 
de direitos da população LGBT de Natal é uma de nossas tarefas primordiais para coletivização das demandas e também uma prerrogativa do nosso Código de Ética profissional, tendo em vista que o conjunto CFESS-CRESS ressalta que a defesa dos direitos dessa população é uma pauta que já faz parte da agenda política do serviço social.

Não apenas nós, assistentes sociais, que atuamos em um serviço direcionado ao atendimento da população LGBT, mas todo o conjunto da categoria tem o dever ético de exercer a profissão "[...] sem ser discriminado/a, nem discriminar, por questões de inserção de classe social, gênero, etnia, religião, nacionalidade, orientação sexual, identidade de gênero, idade e condição física" (CFESS, 1993, p. 24). Em nossa análise, o exercício profissional que naturaliza os processos de LGBTfobia na sociedade contribuirá sobremaneira para reproduzir preconceitos e discriminações.

\section{CONSIDERAÇÕES FINAIS}

A desigualdade, a miséria, a violência não são elementos novos da realidade. São, na verdade, parte importante do que constitui a sociabilidade do capital. O ataque orquestrado pela burguesia heteropatriarcal racista contra a vida de trabalhadores(as), em toda sua diversidade, faz parte do projeto de hegemonia social. Apesar disso, essa realidade se complexifica em períodos como o atual, de crise estrutural do capital e pandemia sanitária que têm atingido o mundo todo.

O Estado capitalista oferece apenas respostas pontuais, pois não pode ameaçar a estrutura, afinal quem mais se beneficia das suas ações é a burguesia, que o comanda. Portanto, não se deve ter ilusão nessa relação estabelecida entre Estado e burguesia, pois, apesar de ser importante a pressão organizada de classe para garantir políticas públicas, uma vez que tais políticas dizem respeito à sua sobrevivência, concretamente, não se deve esquecer que o Estado é capitalista, heteropatriarcal e racista. Por conseguinte, um dos principais violadores dos direitos da população LGBT.

Nessa relação com o Estado, inferimos ser de suma importância a garantia de qualificação dos serviços e equipamentos das políticas públicas para atendimento a esse segmento populacional, a fim de enfrentar a violência institucionalizada por que passa essa população nas mais diversas áreas, como saúde, segurança, educação, assistência social, previdência social e trabalho.

Nesse sentido, formulamos esse trabalho na intenção de refletir sobre os desafios postos ao serviço social para a atuação na defesa de direitos da população LGBT, a partir da experiência no Centro Municipal de Cidadania LGBT de Natal (RN), sob a justificativa de que isso possibilita, por consequência, a qualificação do serviço prestado a essa população. Ademais, refletir sobre esse exercício e as questões que o perpassam nos remete às contradições e limites postos pela realidade, logo, um dos maiores desafios é atuar no sentido de não tratar questões estruturais como questões exclusivamente individuais - a ideia de buscar a essência e fugir da aparência dos fenômenos nunca deixou de ser atual. 
Assim, consideramos que os direitos humanos são inegociáveis, porém, a população LGBT tem sido uma das mais atacadas na conjuntura brasileira com forte avanço ultraconservador e aprofundamento da política ultraneoliberal. Isso, por si só, exacerbaria, sobremaneira, os desafios para a atuação profissional. Mas, a pandemia sanitária gerada pelo coronavírus, somada a atuação de um governo federal e municipal que se desresponsabiliza e atua de forma criminosa, com o negacionismo da ciência e o incentivo da violência e desinformação constante acentuam e escancaram os limites dessa atuação centrada na direção social do projeto ético político do serviço social.

Diante de uma realidade tão dura, seria completamente equivocado se desconsiderássemos o papel fundamental dos movimentos sociais e partidos políticos de esquerda, ou, até mesmo, se nossa atuação estivesse distante dessas organizações da classe trabalhadora, tão indispensáveis para equalizar as desigualdades nessa sociedade e lutar pela sua transformação radical. Ao passo, portanto, que esse é um dos grandes desafios para o exercício profissional, nos seus mais diversos âmbitos, é uma das grandes potencialidades.

Davis (2019) analisa: "[...] se as lutas do passado não tivessem ocorrido, se as pessoas não tivessem erguido a voz, cometido desobediência civil, batalhado e exercido sua influência para remoldar as relações humanas, nosso mundo seria muito mais empobrecido material e espiritualmente" (DAVIS, 2019, p. 55).

Parafraseando a autora (idem), será que poderíamos prever que, em pleno 2020 e 2021, estaríamos passando por uma nova pandemia que impacta a saúde de todas as pessoas no mundo todo? É provável que alguns e/ou algumas pensadores(as) contemporâneos o tenham imaginado, dado o avanço predatório do capitalismo sobre a natureza e a vida das pessoas. Todavia, com absoluta certeza, poderíamos conceber que algo dessa magnitude impactaria de maneira diferente as classes sociais e seus segmentos mais periféricos, uma vez que não estamos, nem nunca estivemos, em solo capitalista brasileiro, todos(as) indistintamente no mesmo barco.

O novo coronavírus põe luz sobre diversas contradições dessa sociedade desigual. Mas, a fórmula apresentada por Davis, apesar de não ser inédita, é indispensável: só a luta coletiva é capaz de transformar a realidade. A resistência individual não é suficiente. O filme Bacurau ${ }^{16}$ já nos ensinou: “Estamos sob ataque”! É hora de reagir!

\section{REFERÊNCIAS}

AGÊNCIA BRASIL. Brasil recebe 2 milhões de doses de hidroxicloroquina dos EUA.

Disponível em: https://agenciabrasil.ebc.com.br/politica/noticia/2020-06/brasilrecebe-dois-milhoes-de-doses-de-hidroxicloroquina-dos-eua. Acesso em: 13 out. 2020.

\footnotetext{
${ }^{16}$ Lançado em 2019, Bacurau é um dos maiores sucessos do cinema nacional deste ano. Direção: Kleber Mendonça Filho e Juliano Dornelles.
} 
ALMEIDA, Silvio Luiz de. Racismo Estrutural. Feminismos Plurais/ Coordenação Djamila Ribeiro. São Paulo: Sueli Carneiro; Pólen, 2019.

ANDERSON, Perry. Brasil à parte: 1964-2019. Trad. Alexandre Barbosa de Souza, et al. 1. ed. São Paulo: Boitempo, 2020.

ANTUNES, Ricardo. Coronavírus: o trabalho sob fogo cruzado. São Paulo:

Boitempo, 2020.

BOULOS, Guilherme. A onda conservadora. In: DEMIER, F.; HOEVELER, Rejane. A onda conservadora: ensaios sobre os atuais tempos sombrios no Brasil. Rio de Janeiro: Mauad, 2016.

CONSELHO FEDERAL DE SERVIÇO SOCIAL (CFESS). Código de Ética do/a Assistente Social. Brasília (DF), 1993. Disponível em:

http://www.cfess.org.br/arquivos/CEP2011_CFESS.pdf. Acesso em: 19 mar. 2021.

DAVIS, Ângela. Justiça para comunidades lésbicas, gays, bissexuais e transgêneras. Margem Esquerda, São Paulo: Boitempo. LGBT. n. 33, out. 2019.

DEMIER, Felipe. Introdução: o barulho dos inocentes: a revolta dos "homens de bem". In: DEMIER, F.; HOEVELER, Rejane. A onda conservadora: ensaios sobre os atuais tempos sombrios no Brasil. Rio de Janeiro: Mauad, 2016.

FEITOSA, Cleyton. Políticas públicas LGBT no Brasil: um estudo sobre o Centro Estadual de Combate à Homofobia de Pernambuco. In: Sexualidad, Salud y Sociedad - Revista Latinoameriana, n. 32, p. 90-118, ago.2019. Disponível em: https://www.scielo.br/pdf/sess/n32/1984-6487-sess-32-90.pdf. Acesso em: 3 out. 2020.

MASCARO, Alysson Leandro. Dinâmica da crise e do golpe: de Temer a Bolsonaro. Margem Esquerda, São Paulo: Boitempo, n. 33, Bolsonaro, maio 2019.

MBEMBE, A. Necropolítica: biopoder, soberania, estado de exceção, política de morte. Tradução: Renata Santini. São Paulo: n-1 edições, 2018.

QUINALHA, Renan. "Em nome de Deus e da família”: um golpe contra a diversidade. In: JINKINGS, I.; DORIA, K.; CLETO, Murilo (orgs.). Porque gritamos golpe?: para entender o impeachment e a crise política no Brasil. 1. ed. São Paulo: Boitempo, 2016.

SOUZA, D. O. As dimensões da precarização do trabalho em face da pandemia de COVID-19. Trabalho, Educação e Saúde, Rio de janeiro, v. 19, 2021. Disponível em: https://www.scielo.br/pdf/tes/v19/0102-6909-tes-19-e00311143.pdf. Acesso em: 19 mar. 2021.

VOTE LGBT. Diagnóstico LGBT+ na pandemia: desafios da comunidade LGBT+ no contexto de isolamento social em enfrentamento à pandemia de Coronavírus. 28 
atuação do Serviço social com população lgbt em contexto... 60170010

jun. 2020. Disponível em: https://medium.com/@box1824/diagn\%C3\%B3stico-lgbt-napandemia-b71c41ca58c6. Acesso em: 20 mar. 2021.

Michael Hudson Dantas concepção, delineamento, análise e interpretação dos dados, redação do artigo e revisão crítica.

Assistente Social do Centro Municipal de Cidadania LGBT de NATAL (RN), Mestre em Serviço Social (PPGSS/UFRN), membro do Grupo de Estudos e Pesquisa em Trabalho, Ética e Direitos (GEPTED/UFRN). Desenvolve pesquisas em torno da diversidade sexual e de gênero, e violências contra a população LGBT+ no Nordeste brasileiro. Tem experiência como Assistente Social na política de Assistência Social e de Direitos Humanos.

Luana Vanessa Soares Pinto de Souza concepção, delineamento, análise e interpretação dos dados, e redação do artigo.

Assistente Social do Centro Municipal de Cidadania LGBT de NATAL (RN), Mestranda em Serviço Social (PPGSS/UFRN), membro do Grupo de Estudos e Pesquisa - Trabalho, Ética e Direitos (GEPTED/UFRN). Tem experiência profissional como Assistente Social na área da Assistência Social e Direitos Humanos.

Samya Katiane Martins Pinheiro redação do artigo e revisão crítica.

Assistente Social do Centro Municipal de Cidadania LGBT de NATAL (RN), Doutoranda do Programa de Pós-Graduação em Serviço Social (PPGSS/UFRN). Mestra em Serviço Social (PPGSS/UFRN), membro da Comissão de Comunicação do CRESS/RN e do Grupo de Estudos e Pesquisa em Trabalho, Ética e Direitos (GEPTED/UFRN). Conselheira do Conselho Municipal de Políticas Públicas sobre Drogas (COMUD) da cidade de NATAL (RN). Tem experiência profissional como Assistente Social na área da Assistência Social e Direitos Humanos. 